\title{
Aging Effects on the Fate and Bioavailability of Cerium Oxide Nanoparticles to Radish
}

\section{(Raphanus sativus L.) in Soil}

\author{
Weilan Zhang ${ }^{1}$, Yongbo Dan ${ }^{2}$, Honglan, $\mathrm{Shi}^{2,3}$, Xingmao $\mathrm{Ma}^{1,3}$ * \\ ${ }^{1}$ Zachry Department of Civil Engineering, Texas A\&M University, TAMU 3136, College
}

Station, TX 77843-3136, USA

${ }^{2}$ Department of Chemistry and Environmental Research Center, Missouri University of Science and Technology, Rolla, MO, 65409, USA

${ }^{3}$ Center for Single Nanoparticle, Single Cell, and Single Molecule Monitoring $\left(\mathrm{CS}^{3} \mathrm{M}\right)$, Missouri University of Science and Technology, Rolla, MO, 65409, USA

*For correspondence:

Xingmao Ma

Zachry Department of Civil Engineering

Texas A\&M University

TAMU 3136

College Station, TX 77843-3136

USA

Email: $\underline{x m a @ \text { civil.tamu.edu }}$ 


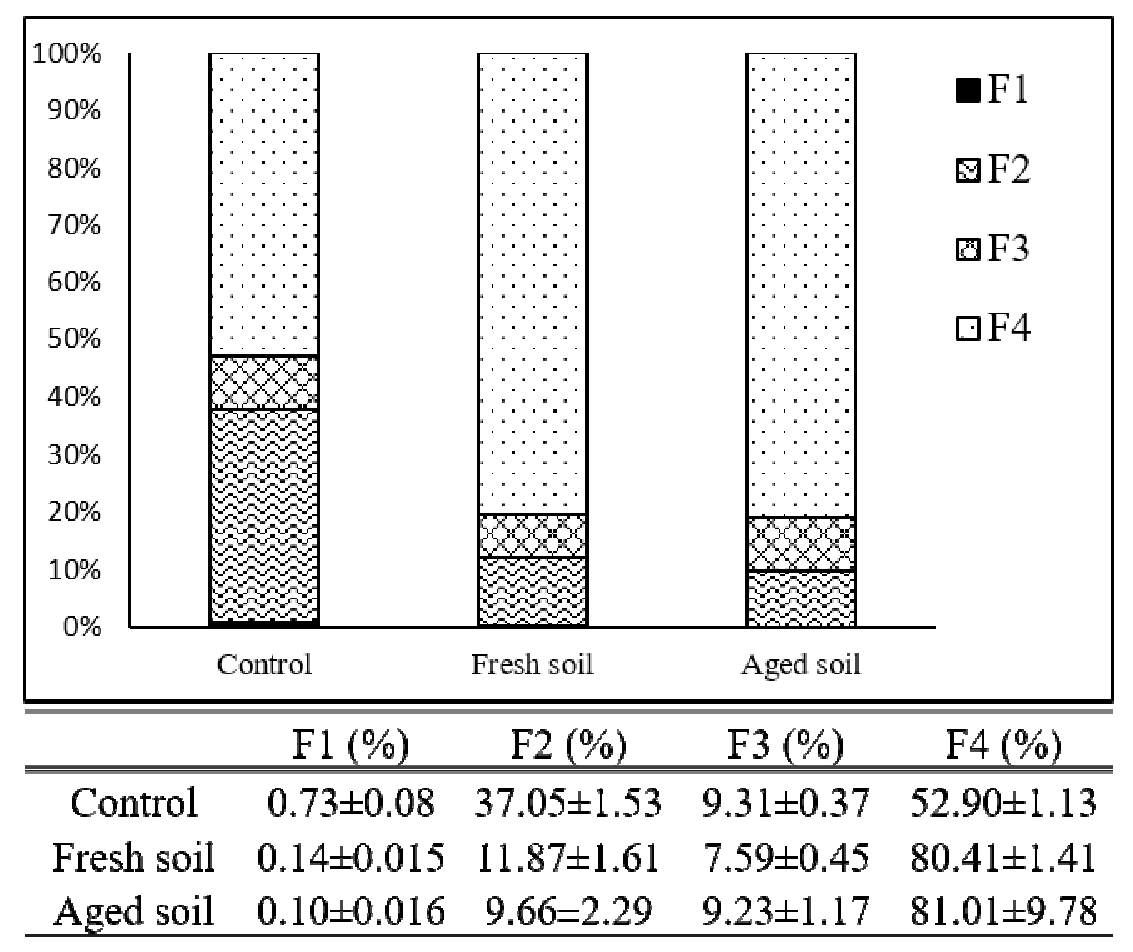

Figure S1. Percentage of cerium fractionation determined by the modified BCR sequential extraction procedure. The results shown on the table beneath the figures represent the average and standard error of three replicates $(n=3)$. The $F 1$ fraction was too small to see in the treated soils. 


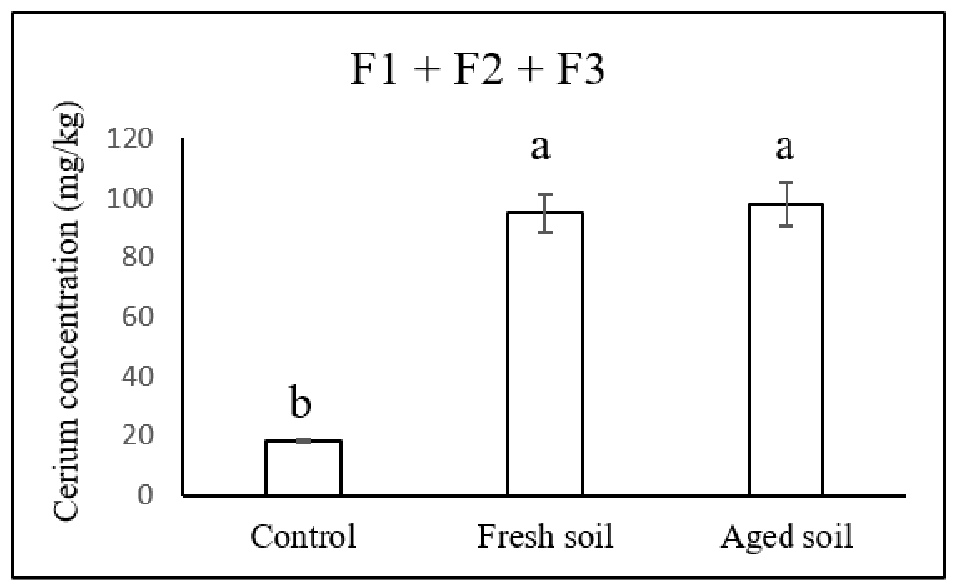

Figure S2. The sum of the first three fractions extracted by modified BCR method in three different soils. 


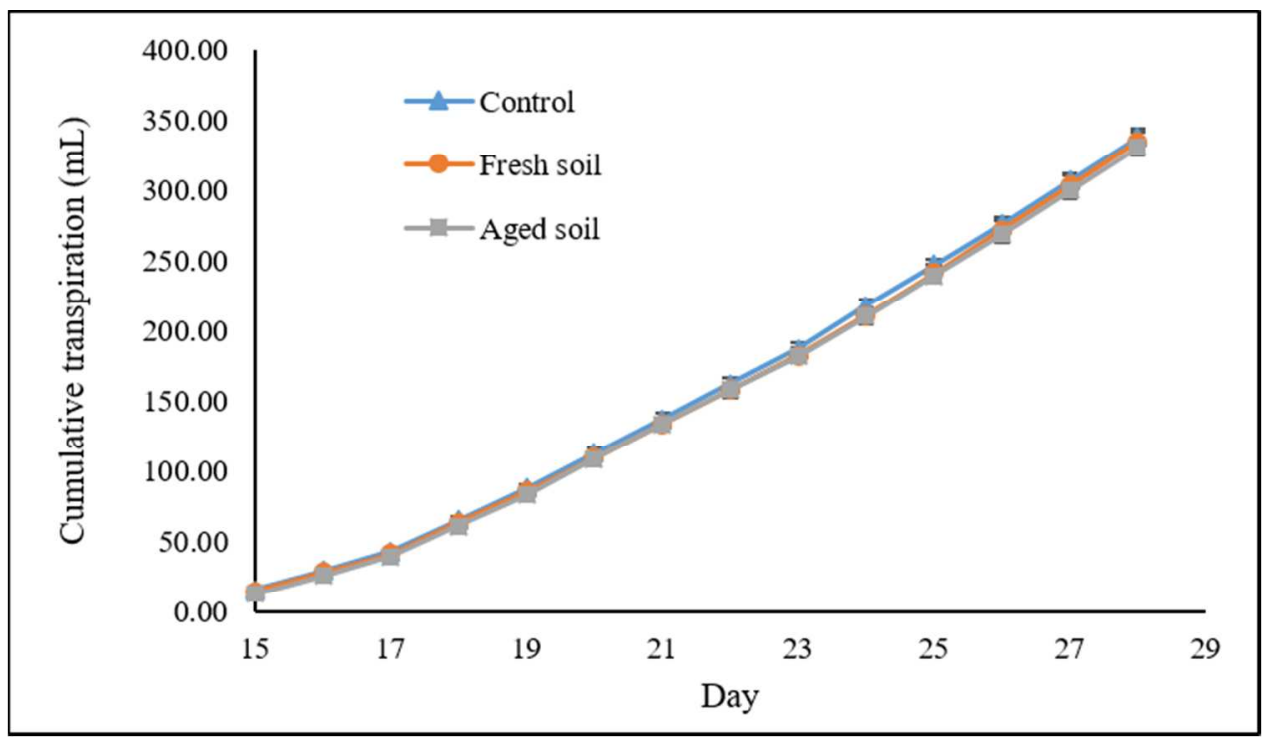

Figure S3. The average accumulative transpiration of radish grown in three different soils $(\mathrm{n}=9)$. Error bars represent standard error. No significant difference was detected between different treatments. 
Table S1. The percent of sand, silt, and clay in the soil used in this study

\begin{tabular}{cc}
\hline & Illinois soil \\
\hline \hline Clay & $19.06 \%$ \\
Silt & $65.14 \%$ \\
Sand & $15.80 \%$ \\
\hline Classification & Silty loam \\
\hline
\end{tabular}

